\title{
The use of opioids for dyspnea in advanced disease
}

\author{
Romayne Gallagher MD
}

\section{Opioids are the drugs of choice for treating dyspnea refractory to disease-specific therapy in advanced disease}

Multiple randomized controlled trials and systematic reviews have shown significant reduction in breathlessness with the use of oral or parenteral opioids in advanced disease. Opioids were found to be significantly better than oxygen in reducing dyspnea in a study involving 46 patients with and without hypoxia who had dyspnea because of advanced disease. ${ }^{1}$

\section{Opioids do not shorten life}

A prospective cohort study involving 725 patients receiving hospice care did not show any significant association between opioid dose, percent change in dosage and survival. ${ }^{3} \mathrm{Re}$ sults from a number of smaller prospective trials support this finding.

\section{Opioids used in appropriate doses do not cause respiratory depression in patients who have dyspnea from advanced disease}

Respiratory depression is defined as a rise in arterial carbon dioxide $\left(\mathrm{PaCO}_{2}\right)$ and a decrease in arterial oxygen $\left(\mathrm{PaO}_{2}\right)$, as well as a decrease in respiratory rate. A study involving 27 patients given opioids for dyspnea from advanced disease showed no significant rise in $\mathrm{PaCO}_{2}$ or fall in $\mathrm{PaO}_{2}$. All patients had significant relief of dyspnea and a reduction in their respiratory rate. ${ }^{2}$ Opioids reduce the work of breathing — hence the decreased respiratory rate — but do not affect alveolar ventilation. Results of other small retrospective studies support this.

\section{The selection of opioid and the dose must be individualized to the patient}

Pharmacogenetic research reveals wide variations in opioid pharmacokinetics that affect patient response to the drug and dose and the occurrence of adverse effects. ${ }^{4}$ Clinically, this means the dose must be individualized according to the analgesic response and adverse effects. Switching to a different opioid should be considered if there are intolerable adverse effects or poor response after appropriate dose titration.

Opioids with active metabolites accumulate in frail older adults and patients with renal failure and can cause significant adverse events

Opioids are excreted through the kidneys. Pharmacokinetic research has shown that opioids with active metabolites can accumulate in frail older adults and patients with renal failure and can cause drowsiness, confusion and delirium. ${ }^{5}$ Opioids with clinically significant active metabolites are codeine, morphine and meperidine. Better choices for these patients are oxycodone, fentanyl, hydromorphone and methadone. Children with advanced disease also require adjustment for pharmacokinetic differences.

CMAJ invites submissions to "Five things to know about ..." Submit manuscripts online at http://mc.manuscriptcentral.com/cmaj

\section{References}

1. Clemens K E, Quednau I, Klaschik E. Use of oxygen and opioids in the palliation of dyspnoea in hypoxic and non-hypoxic palliative care patients: a prospective study. Support Care Cancer 2009; 17:367-77.

2. Clemens KE, Quednau I, Klaschik E. Is there a higher risk of respiratory depression in opioidnaive palliative care patients during symptomatic therapy of dyspnea with strong opioids? J Palliat Med 2008;11:204-16.

3. Portenoy RK, Sibirceva U, Smout R. Opioid use and survival at the end of life: a survey of a hospice population. J Pain Symptom Manage 2006;32:532-40.

4. Somogyi AA, Barratt DT, Coller JK. Pharmacogenetics of opioids. Clin Pharmacol Ther 2007;81: 429-44.

5. Smith HS. Opioid metabolism. Mayo Clin Proc 2009;84:613-24.

Competing interests: Romayne Gallagher has accepted honoraria for educational events on palliative care and pain management sponsored by Purdue Pharma.

This article has been peer reviewed.

Affiliations: Romayne Gallagher is with the Division of Palliative Care, Department of Family and Community Medicine, Providence Health Care, and the Division of Palliative Care, University of British Columbia, Vancouver, BC.

Correspondence to: Dr. Romayne Gallagher, rgallagher@providencehealth.bc.ca

CMAJ 2011. DOI:10.1503/cmaj.110024

A list of resources for opioid prescribing, including a downloadable palliative opioid prescribing tool, is available in Appendix 1 (www.cmaj.ca/lookup/suppl/doi:10.1503 /cmaj.110024/-/DC1). 